\title{
STUDY OF BYPASS RATIO INCREASING POSSIBILITY FOR TURBOFAN ENGINE AND TURBOFAN WITH INTER TURBINE BURNER
}

\author{
Robert Jakubowski \\ Department of Aircrafts and Aircraft Engines \\ Rzeszow University of Technology \\ Powstańców Warszawy Av. 8, 35-959 Rzeszow, Poland \\ tel.: +48178651466 fax: +48178651942 \\ e-mail: robert.jakubowski@prz.edu.pl \\ MTU Aero Engines Poland \\ Tajęcina 108, 36-002 Tajęcina, Poland \\ tel.: +48177710482 \\ e-mail: robert.jakubowski@mtupolska.com
}

\begin{abstract}
Current trends in the high bypass ratio turbofan engines development are discussed in the beginning of the paper. Based on this, the state of the art in the contemporary turbofan engines is presented and their change in the last decade is briefly summarized. The main scope of the work is the bypass ratio growth analysis. It is discussed for classical turbofan engine scheme. The next step is presentation of reach this goal by application of an additional combustor located between high and low pressure turbines. The numerical model for fast analysis of bypass ratio grows for both engine kinds are presented. Based on it, the numerical simulation of bypass engine increasing is studied. The assumption to carry out this study is a common core engine. For classical turbofan engine bypass ratio grow is compensated by fan pressure ratio reduction. For inter turbine burner turbofan, bypass grown is compensated by additional energy input into the additional combustor. Presented results are plotted and discussed. The main conclusion is drawing that energy input in to the turbofan aero engine should grow when bypass ratio is growing otherwise the energy should be saved by other engine elements (here fan pressure ratio is decreasing). Presented solution of additional energy input in inter turbine burner allow to eliminate this problem. In studied aspect, this solution not allows to improve engine performance. Specific thrust of such engine grows with bypass ratio rise - this is positive, but specific fuel consumption rise too. Classical turbofan reaches lower specific thrust for higher bypass ratio but its specific fuel consumption is lower too. Specific fuel consumption decreasing is one of the goal set for future aero-engines improvements.
\end{abstract}

Keywords: aero engines, turbofan engine, combustion engines, aero engine development, turbine inter stage burner

\section{Introduction}

Significant grow of aviation transport, and connected whit this environmental impact of the air traffic directly leads to new challenges, which should be full filed by modern perspective aircrafts. The prediction of commercial air traffic grows presented in work [16] shows that it will be double every 15 years. This generates new challenges for aviation industry to safe continuously growing mobility needs, while the same time preserving resources, mitigating the impact on climate, environment and reducing noise emissions. European aviation companies and research establishments defined targets for the future of air traffic. In 2011, the Flightpath 2050 vision was released which defines the goals to be achieved by the years 2050 [16]. Different technological and research programs was undertaken to reach these goals. To meet the goals the propulsion system improvement takes the crucial position. The results of aero engines improvement study show that in the nearest future the overall pressure ratio should reach 70 and bypass-ratio should be close to 20 [16]. 
The classical turbofan engine (TF) which was introduced to the service in last decade of twenty and first decade of twenty first century are not able to full file these demands. The study of aero engine concepts shows that new generation of commercial turbofan engines will be based on gear fan conception with intercooled core engine $[15,19,20]$. The study of pros and cons of intercooled recuperated core is the object of contemporary research and the results are presented in mentioned works.

The other vision of aero engine improvement is presented in papers $[1,3,4,7,9,11,12,17]$, where the engine with inter-turbines burner (ITB) is studied. The discussion of profits by additional burner application points that the thermal efficiency increasing by cycle modification in such manner that the process is close to isothermal in turbine [11, 17]. The lowering or elimination of turbine cooling flow by additional burner application is studied in [4, 7], while in the classical engine TIT (turbine inlet temperature) growth generates the increasing of cooling air mass flow $[2,5]$. Presented in work $[4,7]$ conception assumed that, the maximum temperature in the engine not exceed hot section material limits and the additional burner generates additional energy for propelling the turbines and producing thrust.

Study of aero-engines emission presented e.g. in $[13,14,18]$ shows that looking for new environmentally friendly propulsion should lead to hybrid concept like presented in [15] or to increase bypass ratio of turbofan engine [16]. The conception of bypass ratio increasing for classical turbofan engine and turbofan with additional combustor is the scope of this work.

\section{Two-combustor turbofan vs. classical turbofan}

The classical turbofan engine (TF) is the main source of propulsion for the contemporary passenger and transport aircrafts (Fig. 1). There are few different types of such engines like two or three spool engine, engine with a gear ore without the gear between the fan and the turbine. By the way, the common feature of all of them is high bypass ratio.

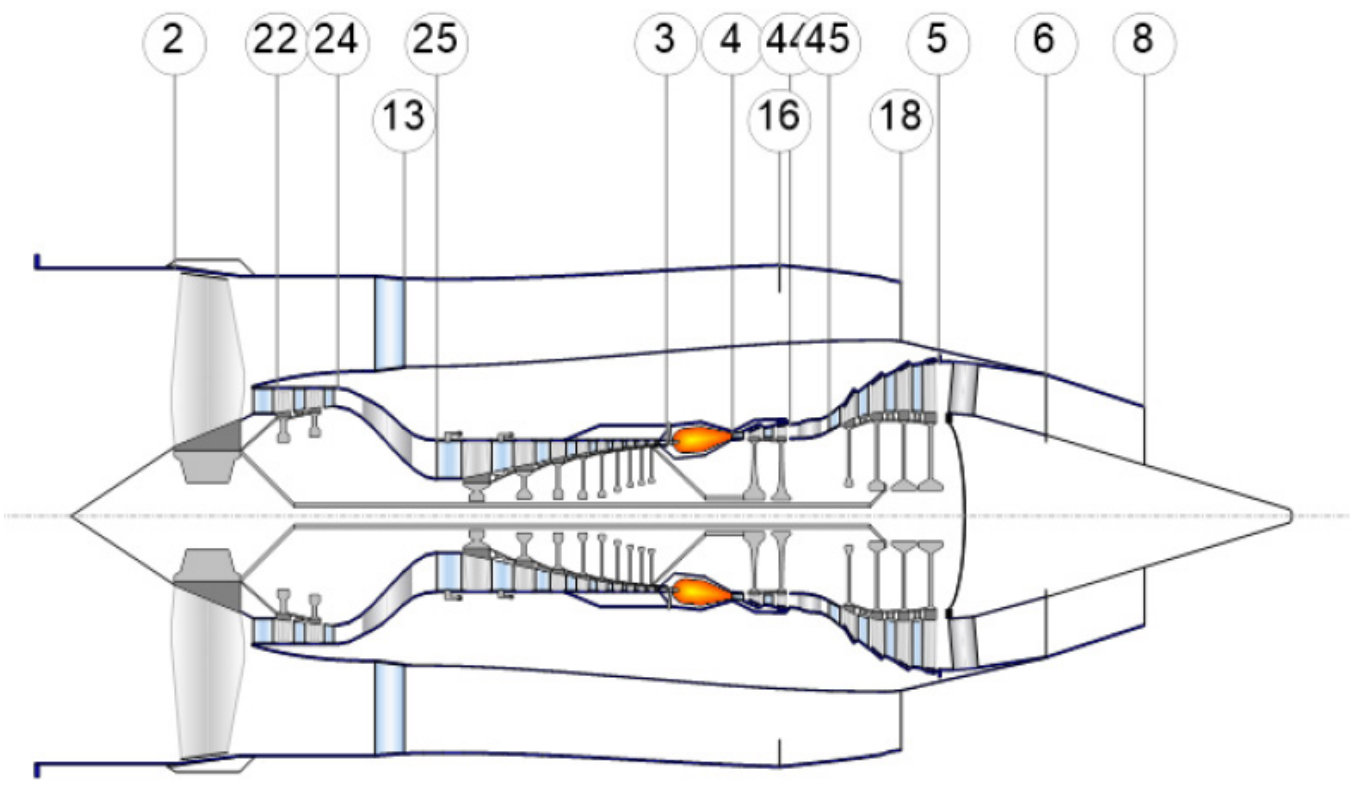

Fig. 1. Schematic diagram of a high bypass ratio turbofan with cut section index [8]

In Fig. 2, the turbofan with inter-turbine burner (ITB TF) is presented. The additional energy insert in the second combustor into mainstream is studied as a big potential to increase bypass ratio. The additional heat supplied in the second combustor should provide the energy needed to propel the growing fan. 


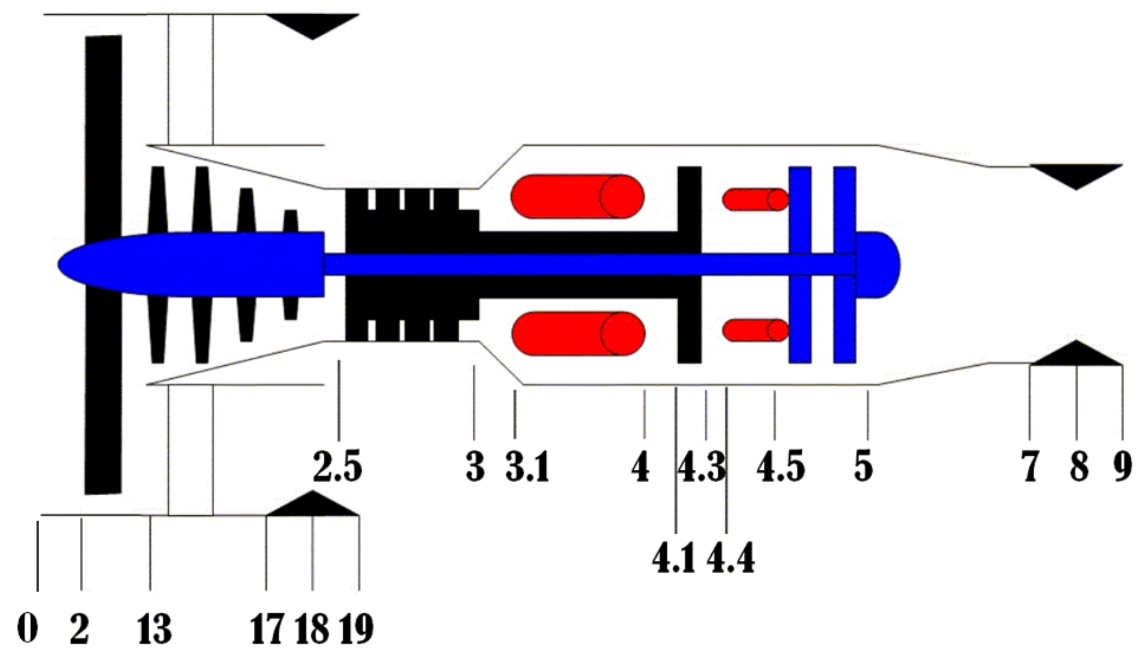

Fig. 2. Schematic diagram of a turbofan with ITB

\section{Classical turbofan limits}

By-pass ratio of contemporary turbofan engines reaches 12 [8]. The conclusion presented in [8] shows that the aerodynamic quality of the turbomachines reached a very high level, and there is only narrow margin to improvement. TIT is already near to theoretical optimum and its increasing will give only slight cycle efficiency improvement, similarly like pressure ratio increasing above 50 . The only way to significant decrease specific fuel consumption (SFC) is bypass ratio grows. According results presented in the paper [8] bypass ratio increasing from 12 to 18 should allow reducing cruise specific fuel consumption about $4 \%$.

The numerical model to study bypass ratio grow for TF engine start from energy balance for low-pressure spool (LPS):

$$
(1+B P R) c_{p} T_{2}\left(\pi_{F}^{\frac{k-1}{k e_{F}}}-1\right)=\left(1+f_{B}\right)\left(i_{45}-i_{5}\right) \eta_{L P S}
$$

where:

$\mathrm{BPR}$ - bypass ratio,

$\mathrm{c}_{\mathrm{p}}-$ constant pressure heat value,

$\mathrm{k}$ - gas isentropic index,

$\mathrm{T}$ - total temperature of gas in specified by index number engine section,

$\pi_{\mathrm{F}}-$ fan pressure ratio in total parameters,

$\mathrm{e}_{\mathrm{F}}-$ fan polytropic efficiency,

$f_{B}-$ fuel to air ratio in burner,

i - gas specific enthalpy in section specified by index number,

$\eta_{\text {LSP }}$ - low-pressure spool mechanical efficiency.

When we assume that the core engine and flight condition are not changed then LPT enthalpy drop $i_{45}-i_{5}$ und temperature of mass flow in the fan inlet $T_{2}$, are not changed too. Therefore, the bypass ratio increasing needs fan pressure ratio decreasing. The fan pressure ratio lowering causes external duct exit pressure lowering which leads to external duct outlet flow jet reduction:

$$
c_{18}=\sqrt{2 c_{p} T_{18}\left(1-\left(\frac{p_{0}}{p_{18}}\right)^{\frac{k-1}{k}}\right)},
$$

where:

$$
p_{18}=p_{0} \pi_{R} \pi_{F} \sigma_{N \_ \text {ext }},
$$


Where:

c - gas velocity in specified engine section,

$\mathrm{p}-$ total pressure in specified engine section,

$\mathrm{p}_{0}$ - ambient pressure,

$\pi_{\mathrm{R}}-$ ram pressure ratio,

$\sigma_{\mathrm{N} \_}$ext - pressure losses coefficient of external nozzle.

Finally, this leads to decrease of engine specific thrust (ST):

$$
S T=\left(\left(1+f_{B}\right) c_{8}+B P R c_{18}-(1+B P R) c_{0}\right) /(1+B P R),
$$

and modify specific fuel consumption (SFC):

$$
S F C=\frac{f_{B}}{S T(1+B P R)} .
$$

The study of bypass ratio increasing influence on the engine parameter change was done for classical TF engine in flight design condition. It was assumed that core engine parameters, LPT, and propulsive nozzle of internal duct are the same. By this way the internal jest stream velocity does not change. Bypass ratio is growing, but connecting with this higher energy consumption is compensated by the fan pressure ratio decreasing. Results of the engine parameters study for flight condition are presented in Tab. 1.

Tab. 1. Bypass ratio increasing influences on engine parameters for flight condition $H=11 \mathrm{~km} \mathrm{Ma=0.8}$ when fan power is constant

\begin{tabular}{|l|lrrrrrrrrr|}
\hline BPR & - & 12 & 13 & 14 & 15 & 16 & 17 & 18 & 19 & 20 \\
\hline$\pi_{F}$ & - & 1.55 & 1.51 & 1.47 & 1.43 & 1.41 & 1.38 & 1.36 & 1.34 & 1.32 \\
c18 & $\mathrm{m} / \mathrm{s}$ & 340.26 & 333.18 & 326.92 & 321.34 & 316.34 & 311.83 & 307.75 & 304.02 & 300.61 \\
$\mathrm{c} 8$ & $\mathrm{~m} / \mathrm{s}$ & 425.32 & 425.32 & 425.32 & 425.32 & 425.32 & 425.32 & 425.32 & 425.32 & 425.32 \\
$\mathrm{~T} 18$ & $\mathrm{~K}$ & 278.89 & 276.36 & 274.16 & 272.24 & 270.54 & 269.04 & 267.69 & 266.47 & 265.37 \\
$\mathrm{p} 18 / \mathrm{p} 0$ & - & 2.25 & 2.18 & 2.13 & 2.08 & 2.04 & 2.00 & 1.97 & 1.94 & 1.91 \\
$\mathrm{ST}$ & $\mathrm{Ns} / \mathrm{kg}$ & 117.14 & 110.05 & 103.72 & 98.05 & 92.93 & 88.29 & 84.06 & 80.19 & 76.68 \\
$\mathrm{SFC}$ & $\mathrm{g} / \mathrm{kN} / \mathrm{s}$ & 14.45 & 14.28 & 14.14 & 14.02 & 13.93 & 13.84 & 13.77 & 13.72 & 13.66 \\
\hline
\end{tabular}

Presented results show that for classical turbofan engine, when the core engine parameters do not change, the LPT turbine will produce the same level of power. To increase bypass ratio fan pressure ratio should be reduced. This leads to decreasing external duct performance. The only profit is specific fuel flow reduction. The negative effect of specific thrust lowering is an engine dimension growth to fulfil the same thrust level. The external dimension $\mathrm{D}_{\mathrm{ext}}$ can be evaluated according continuity equation as:

$$
\frac{\pi}{4}\left(D_{E x t}^{2}-D_{\text {Int }}^{2}\right)=\frac{m_{2}}{\rho_{2} c_{2}},
$$

when inlet mass flow is determined from specific thrust definition:

$$
m=T / S T,
$$

where:

$\mathrm{D}$ - diameter ext - external, int - internal in fan inlet,

$\mathrm{m}$ - inlet mass flow,

$\rho-$ gas density in specified section.

$\mathrm{T}$ - engine thrust.

The calculation of chosen engine parameter for different BPR relative to the engine of BPR $=12$ are presented in Tab. 2. For dimension evaluation, it was assumed that fan inlet internal diameter and velocity are constant. 
The BPR grow up to 20 causes lowering of specific fuel consumption roughly about $6 \%$. In the same time, specific thrust goes down about 35\%. For assuring the same thrust level, the air mass flow through the engine should grow. Therefore, the external diameter should rises almost $20 \%$.

Tab. 2. Bypass ratio increasing influences on engine parameters relative to engine of bypass ratio 12 for flight condition $H=11 \mathrm{~km} M a=0.78$ when fan power is constant

\begin{tabular}{|c|c|c|c|c|c|c|c|c|c|}
\hline BPR_rel & 12 & 13 & 14 & 15 & 16 & 17 & 18 & 19 & 20 \\
\hline$\pi_{F \_ \text {rel }}$ & 1 & 0.9710 & 0.9464 & 0.9252 & 0.9068 & 0.8906 & 0.8763 & 0.8636 & 0.8521 \\
\hline ST_rel & 1 & 0.9395 & 0.8855 & 0.8371 & 0.7934 & 0.7537 & 0.7176 & 0.6846 & 0.6542 \\
\hline SFC_rel & 1 & 0.9884 & 0.9787 & 0.9706 & 0.9639 & 0.9582 & 0.9534 & 0.9495 & 0.9462 \\
\hline $\mathrm{D}_{\text {ext_rel }}$ & 1 & 1.0267 & 1.0529 & 1.0787 & 1.1040 & 1.1289 & 1.1535 & 1.1777 & 1.2016 \\
\hline
\end{tabular}

\section{Bypass ratio increasing for turbofan with inter-turbine burner}

The application of the additional inter-turbines burner is used to increase BPR, but without fan pressure ratio change (decreasing). According previous discussion on equation 1 this will generate increasing of the power produced by LPT. To do this without outlet pressure ratio decreasing $\left(\frac{p_{5}}{p_{a m b}}=\right.$ const $)$ additional energy should be supplied into an additional burner. In this case, pressure ratio in the LPT should be constant; therefore, LPT temperature drop can be expressed as:

$$
\left(\frac{T_{45}}{T_{5}}\right)^{\frac{k}{(k-1) e_{L P T}}}=\pi_{L P T}=\text { const }
$$

where:

$\mathrm{e}_{\mathrm{LT}}$ - turbine polytrophic efficiency,

$\pi_{\mathrm{LPT}}-$ low-pressure ratio turbine pressure ratio.

Enthalpy replacing by temperature in equation 1 allows rearrange it to determine temperature rise in the turbines as a function of bypass ratio for constant LPT pressure ratio:

$$
(1+B P R) c_{p} T_{2}\left(\pi_{F}^{\frac{k-1}{k e_{F}}}-1\right)=\left(1+f_{B}+f_{I T B}\right) c_{p}\left(T_{45}-T_{5}\right) \eta_{L P S} .
$$

Fuel air ratio in ITB can be calculated from equation presented below, when the assumption is done that $\mathrm{T}_{43}=\mathrm{T}_{45} \mathrm{TF}$ (temperature in the HPT outlet for TF is assumed constant in the analysis):

$$
f_{I T B}=\frac{\left(1+f_{B}\right) c_{p}\left(T_{45}-T_{43}\right)}{L H V \eta_{I T B}},
$$

where:

LHV - fuel heat value,

$\eta_{\text {Iтв }}$ - inter-turbines burner thermal efficiency.

In the presented conception external duct speed will be constant for calculating point (fan pressure ratio is constant), but internal duct jet speed will change as a function of $\mathrm{T}_{5}$.

Specific thrust is calculated as:

$$
c_{5}=\sqrt{\frac{T_{5}}{T_{5_{-} T F}}} c_{8_{-} T F}
$$

$$
S T=\left(\left(1+f_{B}+f_{I T B}\right) c_{8}+B P R c_{18}-(1+B P R) c_{0}\right) /(1+B P R),
$$

and specific fuel consumption as:

$$
S F C=\frac{f_{B}+f_{I T B}}{S T(1+B P R)}
$$


Results of the analyses are presented in Tab. 3 and in relative parameters in Tab. 4 . They show that for presented engine conception the additional energy supplied in inter turbines burner causes fuel consumption increasing more than specific trust growing. Finally, SFC grows and this is not satisfied.

Tab. 3. Bypass ratio increasing influences on ITB turbofan engine parameters for flight condition $H=11 \mathrm{~km} \mathrm{Ma=0.78}$

\begin{tabular}{|c|cccccccccc|}
\hline $\mathrm{BPR}$ & & 12 & 13 & 14 & 15 & 16 & 17 & 18 & 19 & 20 \\
\hline $\mathrm{f}_{\text {ITВ }}$ & - & 0.0000 & 0.0022 & 0.0044 & 0.0065 & 0.0087 & 0.0109 & 0.0130 & 0.0151 & 0.0173 \\
$\mathrm{~T}_{45}$ & $\mathrm{~K}$ & 1000.0 & 1074.6 & 1148.9 & 1222.9 & 1296.6 & 1370.1 & 1443.2 & 1516.0 & 1588.5 \\
$\mathrm{~T}_{5}$ & $\mathrm{~K}$ & 562.4 & 604.4 & 646.2 & 687.8 & 729.3 & 770.6 & 811.7 & 852.7 & 893.5 \\
$\mathrm{c}_{8}$ & $\mathrm{~m} / \mathrm{s}$ & 425.3 & 440.9 & 455.9 & 470.4 & 484.3 & 497.8 & 510.9 & 523.7 & 536.1 \\
$\mathrm{ST}$ & $\mathrm{Ns} / \mathrm{kg}$ & 117.20 & 117.89 & 118.45 & 118.91 & 119.29 & 119.60 & 119.87 & 120.08 & 120.27 \\
$\mathrm{SFC}$ & $\mathrm{g} / \mathrm{kN} / \mathrm{s}$ & 14.44 & 14.66 & 14.84 & 15.00 & 15.14 & 15.26 & 15.37 & 15.47 & 15.55 \\
\hline
\end{tabular}

Tab. 4. Bypass ratio increasing influences on ITB turbofan engine parameters relative to engine of bypass ratio 12 for flight condition $H=11 \mathrm{~km} \mathrm{Ma=0.78}$

\begin{tabular}{|l|rrrrrrrrr|}
\hline BPR & 12 & 13 & 14 & 15 & 16 & 17 & 18 & 19 & 20 \\
\hline ST_rel & 1.000 & 1.037 & 1.072 & 1.106 & 1.139 & 1.170 & 1.201 & 1.231 & 1.260 \\
SFC_rel & 1.000 & 1.006 & 1.011 & 1.015 & 1.018 & 1.020 & 1.023 & 1.025 & 1.026 \\
Dext_rel & 1.000 & 0.998 & 0.996 & 0.994 & 0.993 & 0.992 & 0.991 & 0.990 & 0.989 \\
\hline
\end{tabular}

\section{Comparison of bypass ratio increasing influences the performance of TF and ITB TF}

BPR grow influences relative specific trust is shown in Fig. 3. For classical TF ST decreases significantly. This is caused by external duct jet velocity drop down caused by fan pressure ratio lowering. The effect is forced by BPR grow. In ITB TF, specific trust goes up even while BPR grows. Main reason of such situation is internal duct temperature rise which cause that $\mathrm{c}_{8}$ goes up.

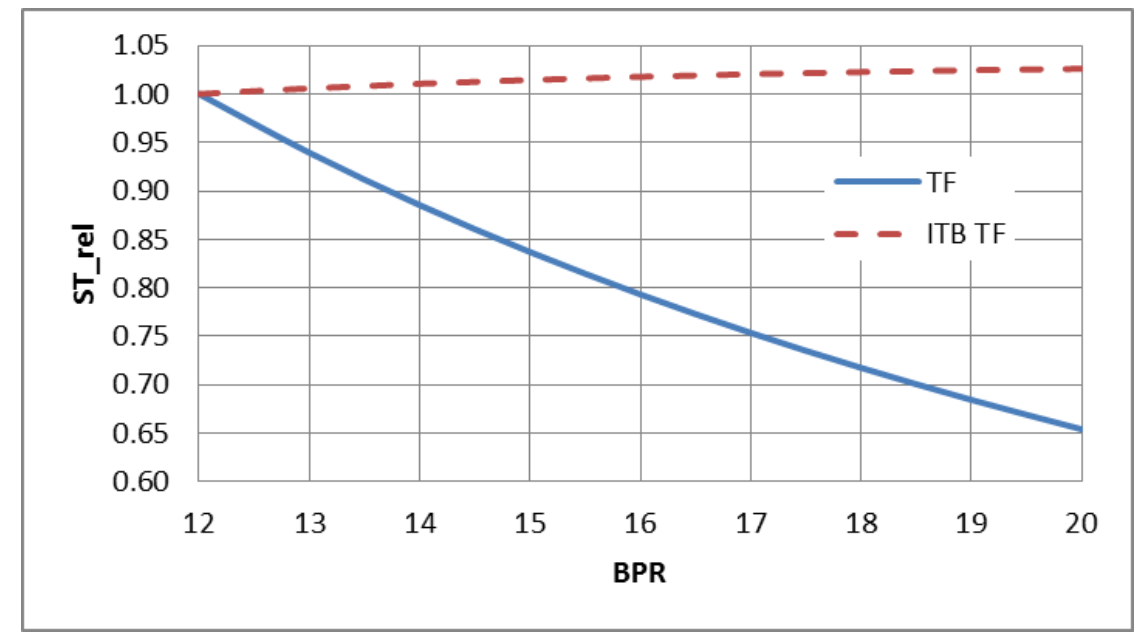

Fig. 3. Relative specific trust vs. bypass ratio for TF and ITB TF

This situation influences the engine mas flow. When the assumption is done that the trust should be on the same level then the mass flow should grow for TF while for ITB TF it can go down. Relative mass flow change to get the same trust for both engine is presented in Fig. 4.

The hypothetical fan external diameter to ensure air mass flow while internal diameter in fan inlet is constant is presented in Fig. 5. It shows that for classical TF engine external diameter should 
grow more than 1.2 time for $\mathrm{BPR}=20$ comparing to engine of $\mathrm{BPR}=12$. In the same condition for ITB TF, external diameter is slightly decreasing.

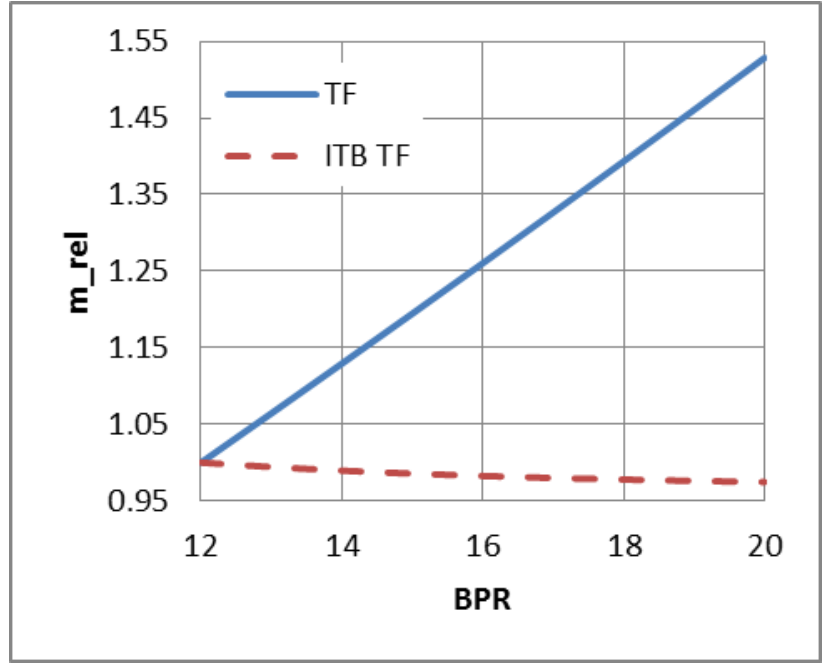

Fig. 4. Relative air mass flow vs. bypass ratio for TF and ITB TF

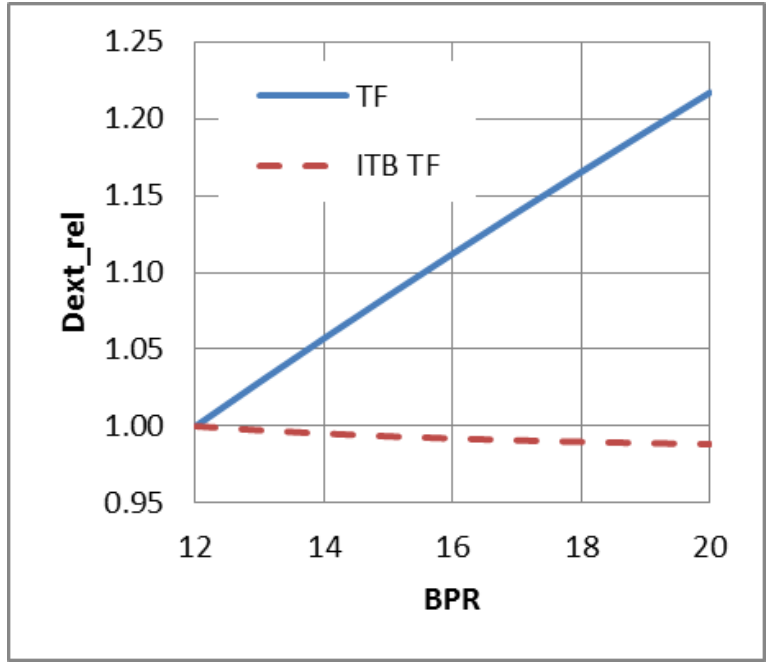

Fig. 5. Relative fan external diameter vs. bypass ratio for $T F$ and ITB TF

Specific fuel consumption comparison is presented in Fig. 6. It shows that classical TF allows to decrease SFC while for ITB TF SFC grows with BPR rising. The reason of SFC growing for ITB $\mathrm{TF}$ is that additional fuel is supply to the engine. Exit gas temperature of internal duct increases, by this way thermal efficiency goes down and finally SFC goes up. Opposite situation is in classical $\mathrm{TF}$ when ducts exit temperature no change and BPR rising.

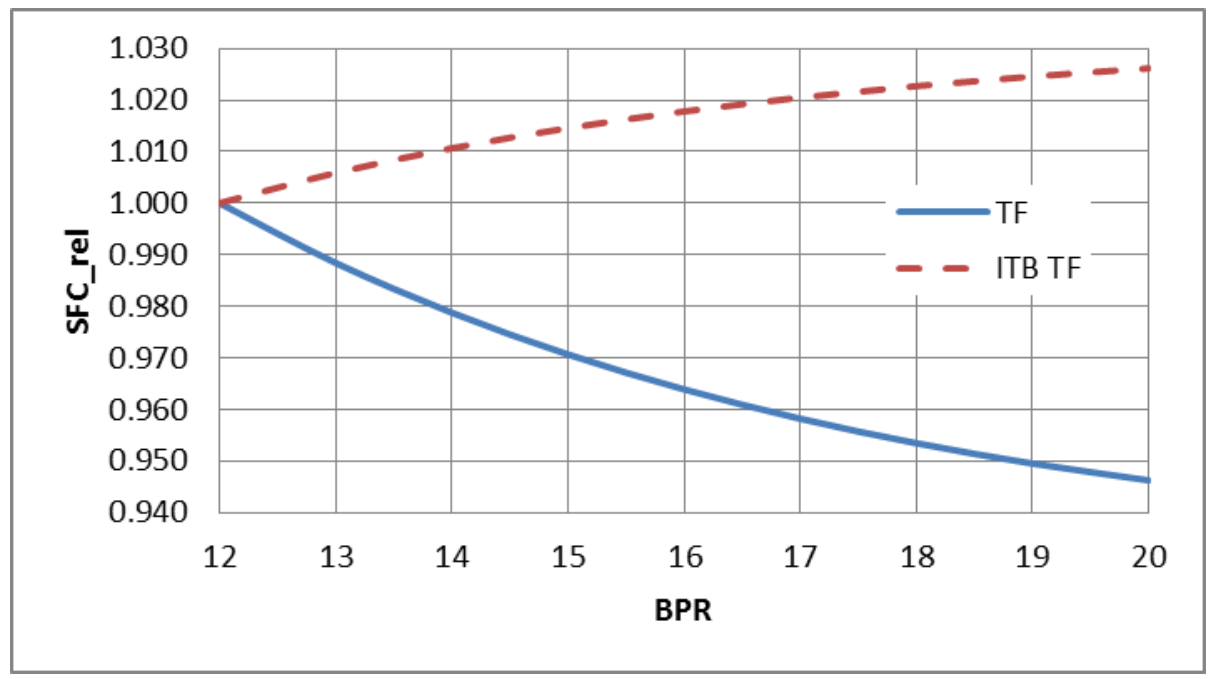

Fig. 6. Relative SFC vs. bypass ratio for TF and ITB TF

\section{Conclusions}

Presented results show that classical TF allows SFC decreasing by BPR increasing. For ITB TF BPR rising causes SFC grow. In this case, ITB TF not allows achieving expected profits. It can be caused by situation that thermodynamic parameters of the internal duct were not changed. The results presented in work [3] show that ITB TF engine cycle can be optimised to achieve lower SFC, but this needs to change internal duct parameters.

ITB TF is more profitable if it is going about ST and connected with it engine external diameter changes with BPR grow. Opposite situation is for TF engine. 
Presented results do not give all picture of possible engines performance changes. It was studied only one case. The big picture can be done after other cases study.

\section{References}

[1] Feijia, Y., Arvind G. R., Off-design Performance of an Interstage Turbine Burner Turbofan Engine, Journal of Engineering for Gas Turbines and Power, 2017.

[2] Horlock, J. H., Watson, D. T., Jones, T. V., Limitations on Gas Turbine Performance Imposed by Large Turbine Cooling Flow, Journal of Engineering for Gas Turbines and Power, Vol. 123, pp. 487-494, 2001.

[3] Jakubowski, R., Analysis of turbofan engine design modification to add inter - turbine combustor, Journal of KONES Powertrain and Transport, Vol. 22, No. 3, pp. 75-82, 2015.

[4] Jakubowski, R., Evaluation of performance properties of two combustor turbofan engine, Eksploatacja i Niezawodność - Maintenance and Reliability, 17 (4): pp. 575-581, 2015.

[5] Jakubowski, R., Modeling and analysis of jet engine with cooling turbine, Journal of KONES, Vol. 19, No. 2, pp. 235-243, 2012.

[6] Jakubowski, R., Modelowanie osiagów silników turbinowych w środowisku MATLAB $z$ wykorzystaniem modeli bloków funkcjonalnych, Technika transportu szynowego, $\mathrm{Nr} 12$, pp. 691-696, 2015.

[7] Jakubowski, R., Two-combustor turbofan engine performance analysis, Journal of KONES Powertrain and Transport, European Science Society of Powertrain and Transport Publication, Vol. 21, No. 3, pp. 141-148, 2014.

[8] Kurzke, J., Fundamental differences between conventional and geared turbofans, ASME Turbo Expo 2009, Power for Land, Sea, and Air, pp. 145-153, 2009.

[9] Lefebvre, A. H., Gas Turbine Combustion, 3th ed., Taylor and Francis Group, LLC, 2010.

[10] Liew, K. H., Urip, E., Yang, S. L., Parametric Cycle Analysis of a Turbofan with Interstage Turbine Burner, Journal of Propulsion and Power, Vol. 21, No. 3, June 2005.

[11] Liew, K. H., Urip, E., Yang, S. L., Mattingly, J. D., Marek, C. J., Performance Cycle Analysis of a Two-spool Separate-exhaust Turbofan with Interstage Turbine Burner, Journal of Propulsion and Power, Vol. 22, No. 2, pp. 411-416, 2006.

[12] Liu, F., Sirignano, W. A., Turbojet and Turbofan Engine Performance Increases Through Turbine Burners, Journal of Propulsion and Power, Vol. 17, No. 3, pp. 695-705, 2001.

[13] Pawlak, M., Kuźniar, M., Analysis of the Wind Dependent Duration of the Cruise Phase on Jet Engine Exhaust Emissions, Journal of KONES Powertrain and Transport, Vol. 25, No. 3, 2018.

[14] Pawlak, M., Kuźniar, M., Majka, A., Pawluczy, J., Emission of selected exhaust compounds in jet engines of a jet aircraft in cruise phase, Combustion Engines, 173(2), pp. 67-72, 2018.

[15] Rao, A.G., Yin, F., van Buijtenen J. P., A Novel Hybrid Engine Concept For Aircraft Propulsion, ISABE-2011-1341, 2011.

[16] Sieber, J., European Technology Programs for Eco-Efficient Ducted Turbofans, ISABE-201520029, 2015.

[17] Sirignano, W. A., Liu, F., Performance Increases for Gas-Turbine Engines Through Combustion Inside the Turbine, Journal of Propulsion and Power, Vol. 15, No. 1, pp 111-118, 1999.

[18] Walsh, P. P., Fletcher, P., Gas Turbine Performance, 2nd ed., Blackwell Publishing and ASME, pp. 227 and 282, Fairfield, NJ 2004.

[19] Xu, L, Gronsted, T., Design and Analysis of an Inercooled Turbofan Engine, Journal of Propulsion and Power, Vol. 29, No. 2, 2013.

[20] Zaho, X., Gronstedt, T., Aero Engine Intercooling Optimization Using a Variable Flow Path, ISABE-2015-20018, 2015.

Manuscript received 26 Febryary 2019; approved for printing 27 June 2019 